28. Rayleigh. -Nature, I88I, Vol. XXV, p. 64.

29. Schoeler, H. - "Die Rot-Blau-Grün, und Grün-Purpur Blindheit." Jahresbericht über d:e Wirksamkeit der früheren Ewersschen Augenklinik, Berlin, 1878.

30. Seebeck.- " Ueber den bei manchen Personen vorkommenden Mangel an Farbensinn." Fogg. Ann. Vol. XL, p. 177-233.

31. Stilling.- "Beiträge zur Lehre von den Farbenempfindungen." Klin. Monatsbl. f. Augenheilk., Vol. XIII, supplement ii.

32. Szokalski. - "Essai sur les sensations des couleurs dans l'état physiologique et pathologique de l'oeil," Annal. d'Oculistique, Vol. III, i840.

33. Tuberville, D.-Phil. Transact., August, 1683 , p. 736.

34. Usher, C. H.- " A Pedigree of Colour Blindness," Trans. of Ophthal. Soc., Vol. XXXII, p. 352 .

35. Waardenburg, P. J. - "The Inheritance of Colour Blindness," Nederl. Tijdschrift voor Genesenkunde, 1914.

\title{
DR. EDRIDGE-GREEN'S THEORIES OF VISION (concluded) \\ BY
}

\section{J. Herbert Parsons,} LONDON.

\section{The Evolution of the Colour Sense}

Dr. Edridge-Green's views on the Evolution of the Colour Sense are based on the following considerations:- (1) Psycho-physical theory; (2) Colour vision in primitive races' (Trans. Ophth. Soc., Vol. XXI, 1901, p. 182) ; (3) The order of disappearance of colours in the spectrum as the intensity is gradually diminished (EdridgeGreen's "Physiology of Vision," p. 169) ; (4) The atavistic theory of colour blindness.

(1) The Psycho-physical Theory._." The sense of sight must have been first developed for those waves which produced their maximum effect upon the sensitive protoplasm" (p. 213). "The wave-length of the physical stimulus is the physical basis of the sensation of colour" (p. 214). "The eye would first discriminate between the rays which are physically most different-the red and violet, that is presuming that the eye had become sensitive to this range" (p. 214). In this stage "the luminosity curve should be the same as the normal sighted" (p. 216). "The next stage in the evolution of the colour sense was when a third colour appeared at the third point of physiological difference, that is, in the centre of the spectrum in the position of the green" (p. 216). "As evolution proceeded the power of differentiation occurred in the regions between the red and the green and the green and the violet until a stage was reached in which a fourth colour, yellow, was seen at the next point of greatest physiological difference" (p. 217). "The next step in the process of evolution occurred when the retinocerebral apparatus was able to differentiate a fresh colour between 
the green and the violet, namely, blue, five definite colours being seen in the spectrum" (p. 217).

This theory of the evolution of the colour sense appears to me to be so extremely speculative as to be of little practical value. In the first place it would apply equally to the auditory sense, and it is well known that all attempts to bring the theory of colour vision into line with that of hearing have failed (Cf. Helmholtz, "Physiologische Optik," 3rd Ed., Vol. II, p. 97).

Second, the "waves which produced their maximum effect upon the sensitive protoplasm" are unknown, for it is obviously a specific stimulus, and if any conjecture is made on this basis the most probable waves would be in the yellow, which are of maximum luminosity.

Third, presuming the sequence was as described, why did yellow precede blue, and why do not orange and indigo appear simultaneously.

Fourth, there is good evidence that the Weber-Fechner law is valid over the ordinary range of visual sensations, though it fails for very high and very low intensities. If it was valid in the early stages of evolution, then the sensations should increase in arithmetical proportion as the stimuli increase in geometrical proportion, or in other words the sensation would vary with the logarithm of the stimulus. The results on this basis would differ. according as the wave-length or the brightness were taken as the criterion. These, however, are pure speculations, and throw little, if any, light on the evolution of colour sense.

Almost simultaneously with Dr. Edridge-Green's first paper on the Evolution of the Colour Sense, McDougall. (Mind, Vol. X, N.S., No. 38, p. 212; quoted in my book, pp. 282-4), dealt with the same subject, also on the basis of a psycho-physical theory. Like Dr. Edridge-Green, he thinks that two colours at the ends of the spectrum were first perceived. He thinks, however, that these were yellow and blue. At a later stage differentiation again took place in the yellow, giving rise to red and green. McDougall is a strong supporter of Young's theory, supplemented by the duplicity theory. On these theories any further differentiation is unnecessary to explain the facts.

Dr. Edridge-Green is strongly of opinion that red and violet were the first colours seen, and that dichromics see only red and violet (pp. 192-195). It is certain, however, that extreme cases of colourblindness, if they limit themselves to two colour names only, which is uncommon, almost invariably speak of blue and yellow. Even normal people generally describe the whole of the blue-violet end of the spectrum as "blue." It is highly improbable that people would call one of the earliest developed colours violet, since this colour is almost unknown in nature. Moreover, there is a considerable 
amount of other evidence in favour of blue and yellow as opposed to red and violet.

(2) Colour Vision in Primitive Races.-This evidence is derived from two sources-philological and anthropological. I have reviewed the literature in my "Introduction to the Study of Colour Vision" (pp. 145, seq.). As evidence of evolution the results are probably valueless. It is unlikely that any material change in the evolution of the colour sense has occurred within historical timés. That evolution in colour terminology has occurred is undoubted, just as the finer shades of meaning of all kinds are progressively reflected in the vocabularies of advancing peoples. Even, however, at the present time, ordinary people, and often educated people, call a greenish blue either green or blue indiscriminately, and orange red or yellow. Of course, this indefiniteness is largely due to carelessness, but it is also fostered by varieties of illumination. Very little importance from the point of view of colour vision is to be attached to crudities of this kind.

I have also collected the comparative (phylogenetic) and 'ontogenetic evidence on the subject (loc. cit., pp. 130 seq., 152 seq.). In both cases the evidence is inconclusive. That relating to the colour vision of animals is very contradictory, and in any case does not support Dr. Edridge-Green's theory. That relating to the development of the colour sense in the child is valueless for the purpose under consideration.

(3) The Order of Disappearance of Colours in the Spectrum as the intensity is gradually diminished.-Dr. Edridge-Green says that they disappear "one by one in the reverse order of the development." This statement is not in accordance with the observations of chromatic thresholds, by Charpentier and others, particularly the very accurate investigations of Abney and Festing, and Abney and Watson. Burch has proved the variability of these phenomena according to the condition of the retina owing to.previous stimulation.

(4) The Atavistic Theory of Colour Blindness.-These speculations lend little support to any theory of colour vision. Since, however, the Young-Helmholtz theory is directly based upon the fundamental assumption which Dr. Edridge-Green makes, viz., the interpretation of colour sensations in terms of physical stimuli, it is not improbable, on that assumption, that colour defects interpreted in terms of the Young-Helmholtz theory afford some evidence as to the evolution of the colour sense, for it is not improbable that a congenital defect of this nature is atavistic.

IX. Simultaneous Contrast, After-Images, and Successive Contrast

The phenomena of After-Images and Colour Contrast are well 
known to have been difficult of explanation by Young's theory, and the efforts of Helmholtz to account for them have never been regarded as satisfactory. Hering's theory offered more plausible explanations, but failed to account for more phenomena of colour vision than it explained. In 1901, McDougall (Mind, Vol. X, N.S., pp. 52, 210, 347), published three papers in which he showed that the facts of after-images and so-called "induction" could be fully explained in consonance with Young's theory. Probably the scant attention which McDougall's exhaustive experiments have received is due to the medium of publication. McDougall's explanation of induction is expressed in terms of Young's theory (see my book, pp. 279-280), which somewhat obscures the fact that it is identical with that adopted by Dr. Edridge-Green, though the latter does not acknowledge the source of the theory. McDougall himself points out that the principle was indeed set forth in 1867 by. Rollet. It has generally been held that the complementary (contrast) colour seen in simultaneous contrast experiments is a purely subjective phenomenon. The Rollet-McDougall explanation is based upon the fact that the white light by which the contrast surface is seen contains light of all wave-lengths, and therefore includes those wave-lengths which give rise to the "induced" colour. Hence the contrast colour is present objectively, and requires no purely psychological explanation. Dr. Edridge-Green also adopts McDougall's explanation of the colour "induced " upon a grey surface, viz., that it is due to the inhibition or subtraction of the inducing colour from the grey.

McDougall's experiments on these peculiarly variable and elusive phenomena of vision cannot be disregarded. His final conclusion may be quoted. "Young's theory," he writes, "if we incorporate with it the hypothesis of the separate white-exciting apparatus having its retinal seat in the rods, as urged by von Kries, Rollet's theory of contrast and the theories of induction and after-images set forth above, explains fully all the phenomena described above; and, with the exception of certain observations of a complex character, very difficult to interpret, such as Müller's experiments on galvanic stimulation of the eyes and some of Professor Sherrington's flicker experiments, I cannot discover any important fact connected with light and colour-vision with which it is incompatible or that it fails to illumine."

With regard to successive contrast Dr. Edridge-Green still lays great stress upon his experiments with Professor A. W. Porter (Proc. Roy. Soc., B., Vol. LXXXV, 1912, p. 434) in spite of the fact that their fallacies have been exposed by Burch (Ophthalmoscope,Vol. XI, 1913, p. 143). In his "Physiology of Vision" Dr. Edridge-Green says: "The greatest precautions were taken to prevent the admixture of stray light in those experiments which were of a 
crucial character"; yet in the original paper the authors say: "In a dark room, in which, however, there was a certain amount of stray light." Burch says: "The phenomena recorded can all be explained when the stray light is taken into account, and they agree perfectly with Young's theory"; and "I have described in my paper 'On the relations of Artificial Colour Blindness to Successive Contrast' (Proc. Roy. Soc., Vol. LXVI, 1900, p.1206) various methods of observing the phenomena of successive contrast with really pure spectral colours, using stimuli no stronger than those employed by Professor Porter and Dr. Edridge-Green. My results are different from theirs, and are in all respects quite in accordance with the theory expounded by Thomas Young."

\section{$\mathrm{X}$. Varieties of Colour Blindness}

It has already been mentioned that Dr. Edridge-Green divides cases of colour blindness into two classes, according as the defect is one of light perception, or one of colour perception or differentiation without any defect in light perception; both defects may be present in the same individual. He cites five varieties of defective light perception (vide supra, p. 367), and classifies the varieties of defective colour perception according to the colour names employed (vide supra, p. 360). Even of a single one of his groups of colour blind, Dr. Edridge-Green says (Ophthalmoscope, Vol. XII, 1914, pp. 77, 79) :- "There may be shortening of the red or the violet end of the spectrum; there may be defective perception for some of the other spectral rays; the luminosity curve may have its maximum at a different place from the normal; there may be defective perception when the image on the retina is diminished in size; and the size of the neutral region is very variable." "(1) There are many degrees and varieties of dichromic vision. (2) There are not two well-defined varieties of dichromic vision, there are innumerable gradations connecting the two. (3) In many cases precisely the same errors are made both by those with and those without defective perception of red, when the rays for, which there is defective perception are not involved. (4) All dichromics are not equally colour blind, that is, one may have a much better hue perception than another. (5) Dichromic vision may be associated with defects of light perception which are also found in cases in which the vision is not dichromic. (6) Dichromics may have a perception of shade and a luminosity curve similar to the normal. (7) Many dichromics match very accurately, their colour perception being sufficient for the purpose when the colours are not too close in the spectrum. (8) The degree of colour blindness varies with the state of health. (9) Colour discrimination is diminished as a whole in dichromic vision. (10) Dichromic vision appears to be due to a defective power of colour differentiation probably 
corresponding to an earlier state in evolution of the colour sense. (11) The two colours seen are red and violet."

His conclusions with regard to "anomalous trichromatic vision" are equally complicated (Proc. Roy. Soc., B., Vol. LXXXVI, 1913, p. 164). "(1) Trichromic vision is not synonymous with anomalous trichromatism. (2) Many persons with otherwise normal colour perception make an anomalous equation. (3) Many colour blind persons (dichromics and trichromics) make an absolutely normal match with no greater mean deviation than the normal. (4) Colour weakness is not characteristic of anomalous trichromatism but of trichromic vision. - (5) Anomalous trichromatism and colour weakness are not synonymous, (6) A large mean deviation indicates colour. weakness. (7) Anomalous trichromatism appears to be due to an alteration in the normal relations of the response to the three colours (lights) used in the equation. If the eye be more or less sensitive to one of the components of the mixed colour whilst the other has its normal effect, an anomalous equation will result. An anomalous equation will also result when the yellow is more allied to green or red than is normal."

If all these statements are valid we may well despair of arriving at any concordant classification of the anomalies of colour vision ; their discrimination must be purely empirical and open to innumerable fallacies. No single theory can- cover so many complex variables, and investigation is reduced to the mere cataloguing of observations by empirical methods. Such collections of facts are but the raw material for the devising of theories. It is a misuse of terms to call an inchoate collection of facts a "theory," but it is only by adopting this solecism that Dr. Edridge-Green can substantiate his oft-repeated statement that he has never yet discovered a fact which is not explained by his "theory," though he has made diligent search. Professor Starling, indeed, seems to realize this aspect of Dr. Edridge-Green's work. In the 1912 edition of his "Principles of Human Physiology," he wrote : "It is very difficult, however, to harmonize the facts of colour blindness with either this (the Young-Helmholtz) or Hering's hypothesis. It is better to abandon hypotheses altogether and to adopt a purely empirical classification of colour vision as has been done by EdridgeGreen. (The italics are mine).*

Fortunately, though colour vision is indeed a difficult subject,

- The section on Vision in the 3rd edition (1920) of Professor Starling's book is writtep by $\mathrm{Dr}$. H. Hartridge, and is excellent. In his discussion of Dr. Edridge-Green's hypothesis (pp. 586-7), he gives this theory a trichromatic bias which, in my opinion, removes many of the objections that can be brought against it, but of which I find little evidence in Dr. Edridge-Green's own writings. I thoroughly agree with Dr. Hartridge's final statement-" With the evidence which has accumulated up to the present before us, there appears to be more in favour of Young's hypothesis than is to be found for its rivals. Further than that it is not at present advisable to go." 
certain groups of facts are concordant in pointing to a hidden orderliness in the midst of the apparent chaos. Such, for example, are the facts of colour mixture and the facts which demonstrate some definite relationship between colour and luminosity. These, the best established correlations in the whole field of colour vision, are those the importance of which Dr. Edridge-Green minimizes or denies.

In these scattered remarks I have attempted to show that many of Dr. Edridge-Green's statements rest upon very doubtful foundations. Stress has been laid upon the evidence against them because he has tacitly ignored it. Dogmatism may win a Pyrrhic victory, but it is only by exhaustive study, for which few have the time or opportunity, or, it may be feared, the inclination, that a sound judgment of the intricacies of the subject can be arrived at. In controversies such as this, however, it is well to remember John Locke's wise words: " Truth certainly would do well enough if she were once left to shift for herself . . . But if truth makes not her way into the understanding by her own light, she will be but the weaker for any borrowed force violence can add to her."

\section{THE THEORY OF VISION \\ BY \\ F. W. EdRIDGe-Green, C.B.E. LONDON.}

In the BRItish Journal of Ophthalmology for July, Mr. J. H. Parsons has commenced his promised attack on my theories of vision and colour vision.

In the case of such a very difficult subject, which has been worked at by the greatest scientific men of the world, many hesitate to form an opinion because they do not know what can be said on the other side. An attack, therefore, of this kind which might otherwise prejudice those only partially acquainted with the subject, greatly strengthens my position when it can be shown that the arguments, many very old, are mostly based on misstatements.

In this article he has dealt with the retinal portion of my theory in which I assume that the rods are not perceptive elements, but are concerned with the formation and distribution of the visual purple. Mr. Parsons does not appear to have read my book very carefully, as nearly all the points he raises have been answered there. He states that some of the evidence in favour of the rods being perceptive elements is as follows: Comparative Anatomy: He states that there are certain animals, as, for instance, the tortoise which have only cones and others possess only rods. This I have 